\title{
Theoretical and Experimental Behavior of Reinforced Concrete Beams Under Torsion
}

\author{
Abdulkadir Cüneyt Aydın, Barış Bayrak
}

\begin{abstract}
In this study, behaviour of reinforced concrete beams under pure torsion have been investigated. Test series comprise of 12 units of reinforced concrete beams of 250x300x1500 mm. Stirrup spacing was selected $80 \mathrm{~mm}$ and $100 \mathrm{~mm}$, concrete class was selected $\mathrm{C20}$ and $\mathrm{C40}$. The test specimens divided into 4 groups. In the test specimens, $16 \mathrm{~mm}$ was used for the longitudinal reinforcement, $8 \mathrm{~mm}$ was used for the stirrup and convensional concrete was used. The torsioal moment capacity, rotation angles of the concrete beams was investigated. In addition to this, the releationship between the torsional moment and rotation angles, the failure torsional moment, the cracks occuring at the beams were examined. For the theorically formula of torsional moment capacity, American Concrete Institute (ACI), Eurocode-2, Turkish Standart, elastic, plastic and skew-bending theories were used. Experimental results and theoretical results of the torsional moment capacity and the failure torsional moment were compared. The best result of torsional moment capacity was obtained at the Turkish Standard. In addition to this, the closest values with tosional moment capacity was obtained at the skew-bending theory. The high concrete class and short stirrup spacing have a good influence on the the torsional moment. Moreover, high concrete class and short stirrup spacing have a favorable influence on the torsional momentrotation angle relationship. The cracks that was occured in the beams due to pure torsion were occured shape diagonal.
\end{abstract}

Keywords - torsion, unit rotation angle, elastic theory, plastic theory, skew-bending theory

\section{Introduction}

The force and bending moments in reinforced concrete create normal stress $(\sigma)$, the shearing force and torsional moment create the shear stresses $(\tau)$. The value of the shearing force varies along the length of the beam depending on the load on the beam. Therefore, the design shearing force to be used in the beam design is important. Torsion is the rotation of the cross-section elements on the same axis under the effect of torsional moments [1].

There are three main stages to analyzing the behaviour of a reinforced concrete member. The first is the pre-cracking stage and the second is the post cracking stage and the third is the crack occurs [2]. Elastic theory, plastic theory and skew-bending theory are the kind of pre-cracking behaviour. In this study, pre-cracking behaviour of reinforced concrete beams was investigated.

Abdulkadir Cüneyt Aydın, Assoc. Prof. Dr.

Ataturk University, Department of Civil Engineering, Faculty of Engineering

Turkey

Barış Bayrak, Ph.D. Candidate

Ataturk University, Department of Civil Engineering, Faculty of

Engineering

Turkey

\section{Torsional Moment}

Torsion is the rotation of the cross-section elements on the same axis under the effect of torsional moments. In reinforced concrete elements, torsional moment is not observed alone to calculate the theorically values of torsional moment was used elastic, plastic and skew-bending theories. According to the elastic theory, the largest shear stress in the cross section occurs at the midpoint of the long edge. The torsional moment value based on elastic theory:

$\mathrm{T}_{\mathrm{e}}=\alpha_{\mathrm{g}} \mathrm{x}^{2} \mathrm{yf}_{\mathrm{ctk}}$

\begin{tabular}{rrrrrrrrrrrr}
\multicolumn{10}{c}{ Table 1. $\alpha$ Values } \\
\hline $\mathrm{y} / \mathrm{x}$ & 1.0 & 1.5 & 2.0 & 2.5 & 3.0 & 4.0 & 6.0 & 8.0 & 10.0 & $\infty$ \\
$\alpha$ & 0.208 & 0.231 & 0.246 & 0.258 & 0.267 & 0.282 & 0.299 & 0.307 & 0.313 & 0.33 \\
\hline
\end{tabular}

The plastic theory is that the collapse is accepted to occur when the maximum tensile stress reaches the tensile strength of concrete. In the plasticity theory, it is assumed that the entire section is plastic and the shear stress is the same at every point of the cross-section. According to plastic theory, torsion calculation is:

$$
\mathrm{T}_{\mathrm{p}}=\alpha_{\mathrm{p}} \mathrm{x}^{2} \mathrm{yf}_{\mathrm{ctk}}
$$

$\alpha_{p}=\left(\frac{1}{2}-\frac{1}{6} \frac{x}{y}\right)$

The third theory is the skew-bending theory where the first crack in the concrete element starts with a 45-degree angle on one of the big side surfaces of the beam. Then, the cracks extend diagonally to the lower and upper surfaces. According to the skew-bending theory, torsion is;

$$
\mathrm{T}_{\mathrm{sb}}=\frac{\mathrm{x}^{2} \mathrm{y}}{\mathrm{a}} \mathrm{f}_{\mathrm{cts}}
$$

When the theorically ultimate torsional moment values are compared the experimental ultimate torsional moment values, the elastic theory gives results over the ultimate torsional moment value, and the plastic theory gives ultimate torsion results less than the ultimate torsional moment values.

Moreover, in this study to calculate the ultimate torsional moment values was used three standards, namely American Concrete Institute (ACI), Eurocode-2 and Turkish Standard (TS). According to the ACI [3] specification, torsional moment is calculated using the following formula.

$\mathrm{T}_{\mathrm{ACI}}=\mathrm{f}_{\mathrm{ys}}\left(\mathrm{A}_{\mathrm{sW}} / \mathrm{s}\right) 2 \mathrm{~A}_{0} \cot \theta$

Torsional moment according to Eurocode-2 [4]: 
$\mathrm{T}_{\mathrm{EU}}=2 \mathrm{~A}_{\mathrm{k}} \sqrt{\frac{A_{\mathrm{gw}} \mathrm{f}_{\mathrm{ywd}}}{s}} \sqrt{\frac{A_{\mathrm{sl}} \mathrm{f}_{\mathrm{y} l \mathrm{~d}}}{\mathrm{u}_{\mathrm{K}}}}$

Torsional moment according to Turkish Standards [5]:

$$
\mathrm{T}_{\mathrm{TS500-2000}}=\frac{\mathrm{A}_{\mathrm{sw}} 2 \mathrm{~A}_{\mathrm{k}} \mathrm{f}_{\mathrm{ywd}}}{\mathrm{s}}
$$

\section{Experiments}

The aim of this study is to evaluate the behavior of reinforced concrete beam elements exposed to torsional moment. And for this purpose, 12 reinforced concrete beams was exposed to the pure torsion. 12 samples were divided into 4 groups. The first group is the beams that was used the C20 conventional concrete class (CC) and $80 \mathrm{~mm}$ web spacing (WS), the second group is the beams that was used the $\mathrm{C} 20 \mathrm{CC}$ and $100 \mathrm{~mm} \mathrm{WS}$ and the third group is the beams that was used the C40 CC and $80 \mathrm{~mm}$ WS and the fourth group is the beams that was used the C40 CC and 100 $\mathrm{mm}$ WS. $16 \mathrm{~mm}$ diameter steel longitudinal reinforcement and $8 \mathrm{~mm}$ diameter steel web was used and this parameter was same for all the samples. The length of the beam samples was chosen as $1500 \mathrm{~mm}$. Cross-section of the samples was selected as $250 \times 300 \mathrm{~mm}$ and dimensions are kept constant for all the samples. The name and properties of samples are shown Table 2 .

\begin{tabular}{ccccc}
\multicolumn{5}{c}{ Table 2. Name and properties of tested beams } \\
\hline $\begin{array}{c}\text { The } \\
\begin{array}{c}\text { Of } \\
\text { Beam }\end{array}\end{array}$ & $\begin{array}{c}\text { Web } \\
\text { Spacing } \\
(\mathrm{mm})\end{array}$ & $\begin{array}{c}\text { Longitudinal } \\
\text { Reinforcement } \\
(\mathrm{mm})\end{array}$ & $\begin{array}{c}\text { Web } \\
(\mathrm{mm})\end{array}$ & $\begin{array}{c}\text { Concrete } \\
\text { Class } \\
(\mathrm{MPa})\end{array}$ \\
\hline $\begin{array}{c}\text { A-1 } \\
\text { A-2 }\end{array}$ & 80 & 16 & 8 & 20 \\
A-3 & 80 & 16 & 8 & 20 \\
B-1 & 100 & 16 & 8 & 20 \\
B-2 & 100 & 16 & 8 & 20 \\
B-3 & 100 & 16 & 8 & 20 \\
C-1 & 80 & 16 & 8 & 20 \\
C-2 & 80 & 16 & 8 & 40 \\
C-3 & 80 & 16 & 8 & 40 \\
D-1 & 100 & 16 & 8 & 40 \\
D-2 & 100 & 16 & 8 & 40 \\
D-3 & 100 & 16 & 8 & 40 \\
\hline
\end{tabular}

Characteristic compressive strength of concrete $\left(f_{c k}\right)$ for $\mathrm{C} 20$ is $22 \mathrm{MPa}$ and compressive strength of concrete for $\mathrm{C} 40$ is $39 \mathrm{MPa}$ and design compressive strength of concrete $\left(\mathrm{f}_{\mathrm{cd}}\right)$ is $26.7 \mathrm{MPa}$. Design strength $\left(\mathrm{f}_{\mathrm{yd}}\right)$ of the reinforcement that was used in the samples was $191 \mathrm{MPa}$. The details of the longitudinal reinforcement and web are shown in Figure 1.
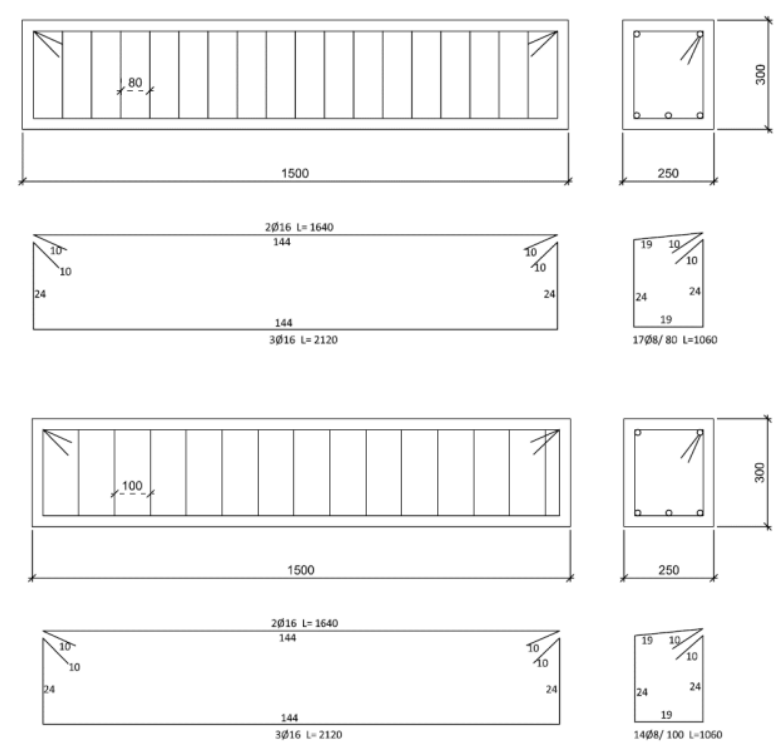

Figure 1. The details of longitudinal reinforcement and web

The tested beams were cured during 28 days. After 28 days, the torsional moment was carried out to the beams. Three LVDTs were connected to the right and three to the left of the sample for measuring deformation and bending under the applied load. The experiment setup intended to create the torsional moment in the beam samples to be subjected to the torsion. Two steel plates in the form of hollow boxes with a depth of $300 \mathrm{~mm}$ were used on the right and left ends of the beam. Figure 2 and 3 show the experimental setup and loading setup.

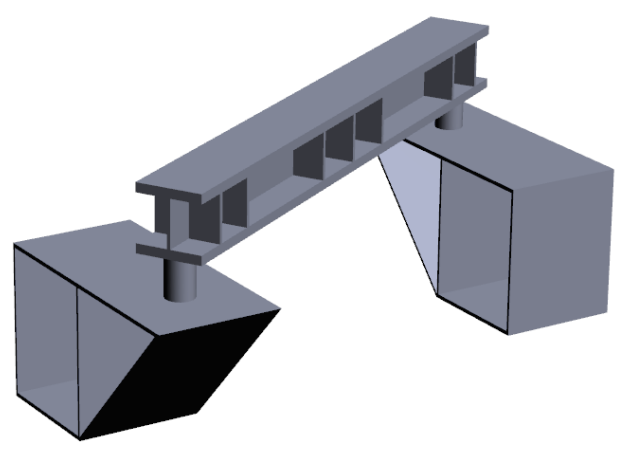

Figure 2. Experimental setup 


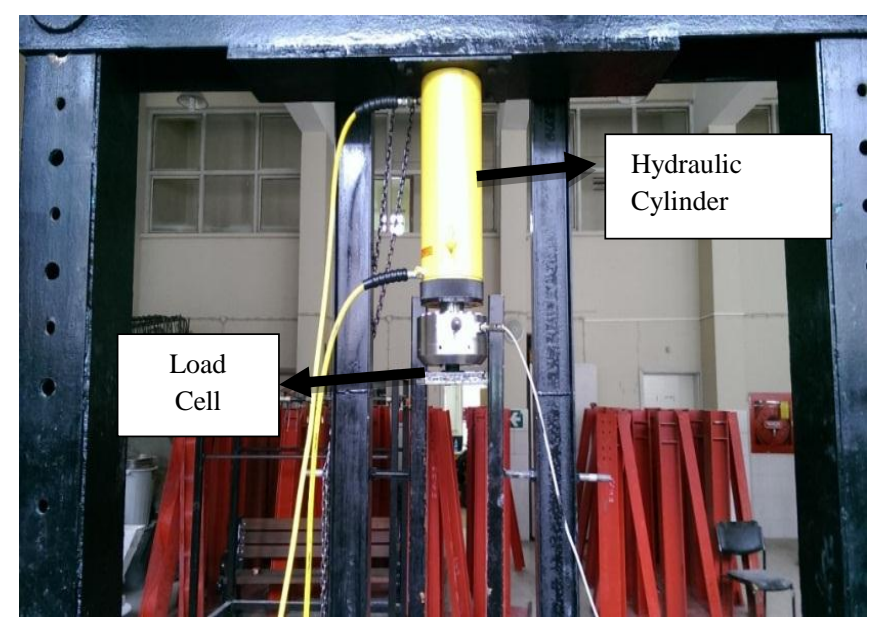

Figure 3. Loading setup

\section{Results}

\section{A. Ultimate torsional moment}

The experimental ultimate torsional results of the beams exposed to the pure torsion are shown Table 3 and Table 4. Table 3 shows the experimental ultimate torsional moment result and the calculated results according to the elastic, plastic and skew-bending theory. Table 4 shows the experimental ultimate torsional moment results and the calculated results according to the ACI, EU-2 and TS.

Table 3. Elastic, plastic, skew-bending and ultimate torsional moment

\begin{tabular}{cccccc} 
The \\
$\begin{array}{c}\text { Name } \\
\text { of } \\
\text { Beam }\end{array}$ & $\begin{array}{c}\text { Elastic } \\
\text { Theory } \\
(\mathrm{kNm}))\end{array}$ & $\begin{array}{c}\text { Plastic } \\
\text { Theory } \\
(\mathrm{kNm}))\end{array}$ & $\begin{array}{c}\text { Skew- } \\
\text { Bending } \\
\text { Theory } \\
(\mathrm{kNm})\end{array}$ & $\begin{array}{c}\text { The } \\
\text { Ultimate } \\
\text { Torsional } \\
\text { Moment } \\
\mathrm{T}_{\mathrm{u}}(\mathrm{kNm})\end{array}$ & $\begin{array}{c}\text { Average } \\
\text { Torsion } \\
\text { Value } \\
(\mathrm{kNm})\end{array}$ \\
\hline $\mathrm{A}-1$ & 6.51 & 10.83 & 12.5 & 11.20 & \\
$\mathrm{~A}-2$ & 6.51 & 10.83 & 12.5 & 11.33 & 11.71 \\
$\mathrm{~A}-3$ & 6.51 & 10.83 & 12.5 & 12.60 & \\
$\mathrm{~B}-1$ & 6.51 & 10.83 & 12.5 & 11.90 & \\
$\mathrm{~B}-2$ & 6.51 & 10.83 & 12.5 & 10.60 & 11.47 \\
$\mathrm{~B}-3$ & 6.51 & 10.83 & 12.5 & 11.90 & \\
$\mathrm{C}-1$ & 8.95 & 14.89 & 17.2 & 12.18 & \\
$\mathrm{C}-2$ & 8.95 & 14.89 & 17.2 & 16.10 & 14.07 \\
$\mathrm{C}-3$ & 8.95 & 14.89 & 17.2 & 13.92 & \\
$\mathrm{D}-1$ & 8.95 & 14.89 & 17.2 & 14.20 & \\
$\mathrm{D}-2$ & 8.95 & 14.89 & 17.2 & 15.20 & 13.38 \\
$\mathrm{D}-3$ & 8.95 & 14.89 & 17.2 & 10.74 & \\
\hline
\end{tabular}

The in the Table 3, we can see the discrepancy between the calculated and the measured values. In the Table 3, the best ultimate torsional result was get to D-2 samples. There are direct proportion between concrete class, web spacing and ultimate torsional moment. As shown in Table 3, sample C-2 reached the maximum ultimate torsional moment value. This is a result of the factors mentioned earlier. Referring to Table 3, the greatest torsional moment values were achieved by $\mathrm{C}$ series. The closest value to the theoretical value was get to the skewbending theory. The values that was calculated form skewbending theory are close to the experimental value. The values that measured were higher than the values that was calculated according to the elastic theory. The values that measured were lower than the values that was calculated according to the plastic theory.

Table 4. Comparison of experimental ultimate torsional moment and ultimate torsional moment according to the standard

\begin{tabular}{ccccc}
\hline & $\begin{array}{c}\mathbf{T}_{\text {EU }} \\
(\mathbf{k N m})\end{array}$ & $\begin{array}{c}\mathbf{T}_{\text {ACI }} \\
(\mathbf{k N m})\end{array}$ & $\begin{array}{c}\mathbf{T}_{\mathrm{TS}} \\
(\mathbf{k N m})\end{array}$ & $\begin{array}{c}\mathbf{T}_{\text {EXPERiMENTAL }} \\
(\mathbf{k N m})\end{array}$ \\
\hline A-1 & 6.68 & 7.62 & 10.94 & 11.20 \\
$\mathrm{~A}-2$ & 6.68 & 7.62 & 10.94 & 11.33 \\
$\mathrm{~A}-3$ & 6.68 & 7.62 & 10.94 & 12.60 \\
$\mathrm{~B}-1$ & 5.97 & 7.62 & 8.75 & 11.90 \\
$\mathrm{~B}-2$ & 5.97 & 7.62 & 8.75 & 10.60 \\
$\mathrm{~B}-3$ & 5.97 & 7.62 & 8.75 & 11.90 \\
$\mathrm{C}-1$ & 6.68 & 10.78 & 10.94 & 12.18 \\
$\mathrm{C}-2$ & 6.68 & 10.78 & 10.94 & 16.10 \\
$\mathrm{C}-3$ & 6.68 & 10.78 & 10.94 & 13.92 \\
D-1 & 5.97 & 10.78 & 8.75 & 14.20 \\
$\mathrm{D}-2$ & 5.97 & 10.78 & 8.75 & 15.20 \\
D-3 & 5.97 & 10.78 & 8.75 & 10.74 \\
\hline
\end{tabular}

It is obvious from Table 4. that the values are calculated according to the standards give unconservative result. It is also illustrate from Table 4 that the closest values are given by TS. The average of ultimate torsional moment show that TS is more successful in ultimate torsional moment comparing other standards. The values that were calculated according to the EU and ACI are lower than experimental values. There was a problem of obtaining different results from the values calculated according to the standards. The results in this study were also conducted in order to provide benefits to engineers encountering this problem. On the other hand, it is illustrate from Table 4 that the values were calculated according to the standards are different each other. The reason of different values between experimental and calculated in the Table 5 is that the torsional moment has impact alone the subjects of academic research more and during the test program torsional moment has been impacted to the samples.

\section{B. Relationship between Torsional Moment and Rotation Angle}

In this part, relationship between torsional moment and rotation angle was investigated. Figures 4, 5, 6 and 7 include the graphs of the test samples between torsional moment-rotation angles. $x$ axis of the graphic is the unit angle of rotation and the $y$ axis of graphic is the ultimate torsional moment value. The line is nonlinear on the graphics.

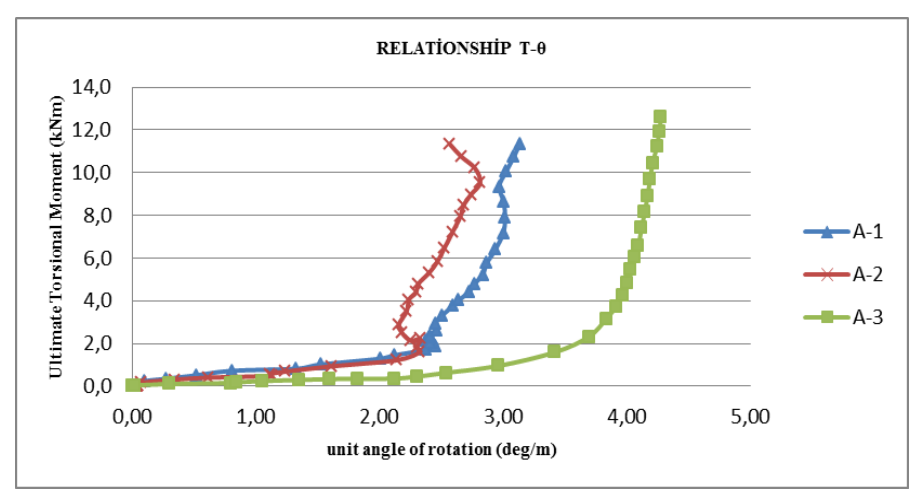

Figure 4. Comparison of torsional moment and unit angle for A samples. 


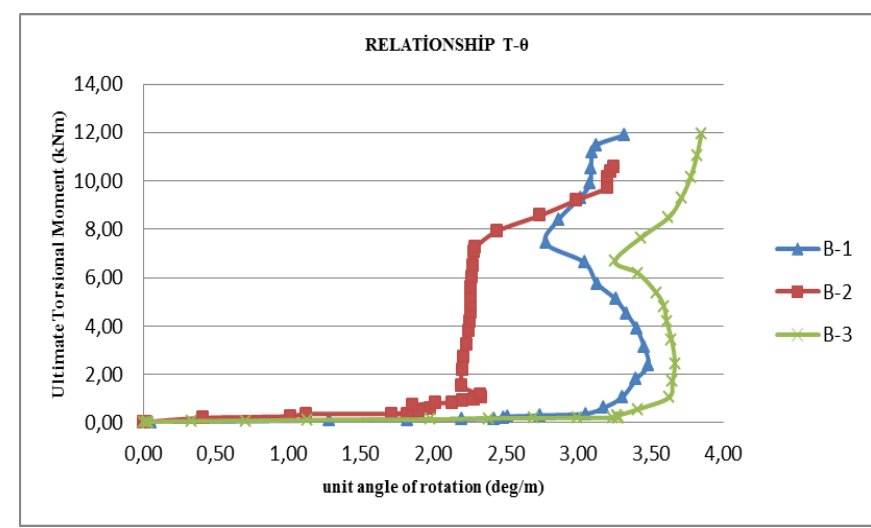

Figure 5. Comparison of torsional moment and unit angle for B samples.

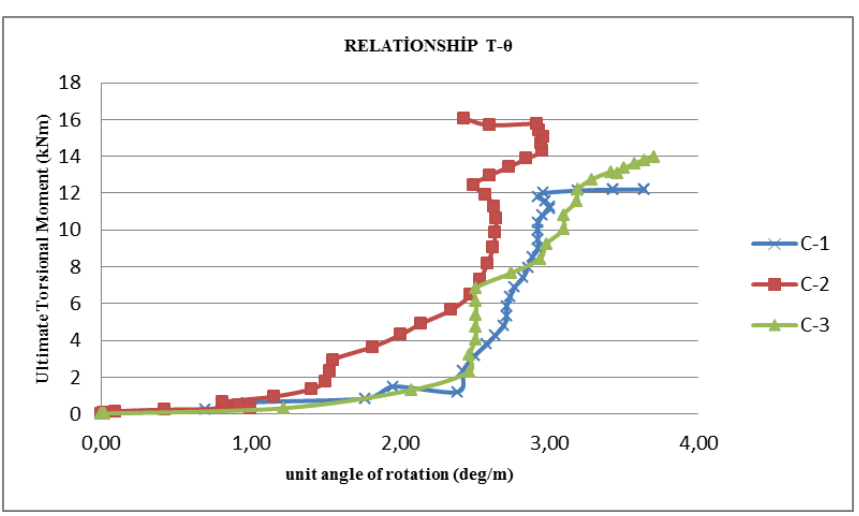

Figure 6. Comparison of torsional moment and unit angle for $\mathrm{C}$ samples

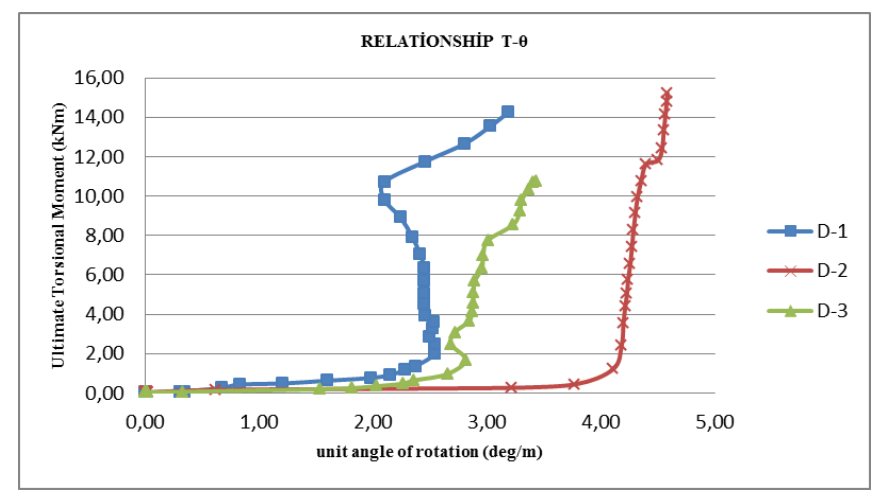

Figure 7. Comparison of torsional moment and unit angle for D samples

The three test groups in the samples in the series CC4SS8 also had similar values. In their study, W. Pawlak and Kaminski [6] have investigated between the between the torsional moment and the rotational angle in the beam supposed to the pure torsion. W. Pawlak and Kaminski [6] investigated the impact of beam sections on torsional moment and rotational angle in their studies. This study investigated the effect of web ratio and concrete class on ultimate torsional moment and rotational angle. The samples of A series have much unit angle of rotation from the samples of B series. The samples that is $80 \mathrm{~mm}$ diameter as web spacing have less unit angle of rotation from the samples $100 \mathrm{~mm}$ diameter as web spacing. Hence, we can see that there are inverse proportion between the unit angle of rotation and web spacing. Low web spacing have a positive impact under the unit angle of rotation and ultimate torsional moment.

\section{v. Conclusions}

It was observed that the samples that had higher strength capacity as concrete class had higher ultimate torsional moment capacity. It was determined experimentally that $\mathrm{C}$ and $\mathrm{D}$ series had higher torsional moment capacity than A and B series. It was observed experimentally that low web spacing had a positive impact under the ultimate torsional moment. The result show that the samples is $80 \mathrm{~mm}$ diameter as web have $15 \%$ higher ultimate torsional moment than the samples is $100 \mathrm{~mm}$ diameter as web. It was determined that to reduce web spacing had increased ultimate torsional moment about $2 \%$ at the A and B series. Similarly to reduce web spacing had increased ultimate torsional moment about $5 \%$ at the $\mathrm{C}$ and $\mathrm{D}$ series.

When the values were calculated according to the elastic theory, plastic theory and skew-bending theory were compared experimental values, skew-bending theory was the closest to reality results. In the calculation of torsional moment with plastic theory, the beam shows plastic behavior at the moment of collapse, yet the collapse occurring without torsion is not entirely plastic. Thus, the experimental results remained below the torsional moment value calculated with plastic theory. In elastic theory, the largest shear stresses occur at the midpoint of the long edge. Since the behavior of concrete is either not exactly elastic or plastic, the elastic theory gives results over the torsion capacity, and the plastic theory gives results less than the torsion capacity. So, skew-bending theory is the closest model for fracture mechanic. At USA, skew-bending theory has been based on to calculate torsional moment since 1970 . But at Europe, the blending of the elastic and plastic theories has been based on to calculate torsional moment.

The ultimate torsional moment values were measured experimentally were compared to the values that were calculated according to the ACI, EU-2 and TS. The closest values were get to according to the TS. The ultimate torsional moment results were calculated according to the ACI, EU-2 and TS are not similar each other. Because of this, different theory is used to calculate torsional moment at the each standard.

\section{References}

[1] Doğangün, A., Betonarme yapıların hesap ve tasarımi: DBYBHY-2007 TS500-2000 ve Deprem yonetmeligi-2007'ye uygun. 2008, İstanbul: Birsen yayınevi. 6. Bask1,842s.

[2] Csikós, Á. and I. Hegedûs. Torsion of reinforced concrete beams. in Proceedings of the 2nd international PhD symposium in civil engineering. Budapest. 1998.

[3] Committee, A., A.C. Institute, and I.O.f. Standardization. Building code requirements for structural concrete (ACI 31808) and commentary. 2008. American Concrete Institute.

[4] EU, B., 1-2: 2004 Eurocode 2: Design of concrete structuresPart 1-2: General rules-Structural fire design. European Standards, London, 2004.

[5] TS500-2000, Türks Standartlarl 2000.

[6] Kamiński, M. and W. Pawlak, Load capacity and stiffness of angular cross section reinforced concrete beams under torsion. Archives of Civil and Mechanical Engineering, 2011. 11(4): p. 885-903. 